\title{
Global Socio-Economic and Environmental Dimensions of GM Maize Cultivation
}

\author{
József Popp ${ }^{1}$, Zoltán Lakner ${ }^{2}$ \\ ${ }^{1}$ Faculty of Applied Economics and Rural Development, University of Debrecen, Debrecen, Hungary; ${ }^{2}$ Department of Food Eco- \\ nomics, Faculty of Food Sciences, Budapest Corvinus University, Budapest, Hungary. \\ Email: poppj@agr.unideb.hu \\ Received February $18^{\text {th }}, 2013$; revised March 22 ${ }^{\text {nd }}, 2013$; accepted April $6^{\text {th }}, 2013$ \\ Copyright (C 2013 József Popp, Zoltán Lakner. This is an open access article distributed under the Creative Commons Attribution \\ License, which permits unrestricted use, distribution, and reproduction in any medium, provided the original work is properly cited.
}

\begin{abstract}
The increased population density, coupled with changes in dietary habits in developing countries towards high quality food and the increasing use of grains for livestock feed is projected to increase demand for food production by $70 \%$ by 2050. Crop yields would continue to grow but at a slower rate than in the past. Yield growth will play an important role as only a slow expansion of agricultural land is expected. Future yield increases on lands currently supporting high production levels must come from continued yield enhancing genetic modifications. The most important grain and feed is maize. Genetic improvement has not only contributed to yield increases but also to other desirable plant components such as resistance to lodging and tolerance to increased plant populations, insects, and diseases. Maize production has increased from 200 million tons in 1960 to over 800 million tons in 2011 but has not changed very much recently. The reviews suggest that the overall assessment of farm-level costs and benefits of GM maize has severe limitations. Nonetheless, GM maize is a potential tool to increase farmers' income and thus might contribute to poverty reduction and sustainable social and rural economic development, especially in developing countries. The results support the contention that the adoption of GM maize leads on average to a higher economic performance, i.e., benefits, for farmers than conventional (non-GM) crops. An important finding of the analysis is that the kind and magnitude of benefits are heterogeneous across crops, traits, countries and regions. However, while the literature on the economic impact of GM crops has grown in recent years there is still a need for more comparative studies across space and time in order to pin down these impacts and allow for a better assessment of the contribution that this technology can make to sustainable development.
\end{abstract}

Keywords: Food Security; Yield Improvement; GM Maize; Economic Benefits

\section{Introduction}

Since 1996, when the first genetically modified (GM) soybean was harvested, biotechnology and its adaptations by the food industry have become one of the most controversial and most disputed topics. However, the adoption of GM crops is occurring at a rapid pace. The global area planted to GM crops in 1996 was approximately 1.7 million hectares. GM crop production has increased each year since then, with an estimated 160 million hectares of GM crops planted in 2011 which represented 10\% - 11\% of global cropland. Biotech crops are accepted for import for food and feed use and for release into the environment in 60 countries, including major food importing and exporting countries. The major GM crops-soybeans, maize, cotton and rapeseed-are also those crops that are the most heavily traded internationally, providing vital export re- venues for many countries and industries but also providing a crucial supply of cheap feed and fibres for many importing countries. Almost all of the global biotech crop area consists of soybeans, maize, cotton and canola. In 2011, GM soybeans accounted for the largest share (47\%), followed by maize (32\%), cotton (15\%) and canola (5\%). In terms of the share of total global plantings to these four crops, biotech traits accounted for $75 \%$ of soybean plantings, followed by cotton ( $82 \%)$, maize (32\%) and canola (26\%).

The most important grain and feed is maize with a world production of around $820-860$ million tons a year. Biotech maize occupied $32 \%$ of the 158 million global hectares of maize, however, the adoption rate of GM maize was $90 \%$ in the USA, $65 \%$ in Argentina and the USA and $50 \%$ for the summer maize and $65 \%$ for the 
winter maize in Brazil. These three countries are the the world's three largest maize exporters with above $80 \%$ share of world maize trade. Cultivation of GM crops cannot be seen in isolation from its geographical, economic and social context. The information on socio-economic aspects of GM maize cultivation is incomplete and a full picture of the state of knowledge is lacking. This is particularly relevant in the current economic crisis, where efficiency gains and food availability and sustainability in the wider sense acquire an acute significance. The industry has also a role in engaging in corporate social responsibility as a tool to build trust in the technology and to develop products with sustainability impact assessments (social, environmental and economic impacts) addressing the co-existence aspects as well.

\section{Materials and Methods}

The paper is based on publication addressing the socioeconomic and environmental effect of GM maize cultivation. Data published in various international journals and books were used in the analysis. The database of FAO, National Research Council, European Commission and IWMI has also been used in the examination. The literature on the impacts of GM crops is already substantial. Several reports have addressed the effects of GM maize on the environment and on human health. However, the effects of agricultural biotechnology at the farm levelthat is, from the point of view of the farmer-have received much less attention. Furthermore, there is a lack of available publications for developing countries and there are only few published accounts for GM performance in English in those countries. And there is a lack of publications on farm-level GM maize benefits in Europe with the exception of Spain due to the small adoption rates of GM maize in Europe. The use of individual studies is furthermore hampered by the fact that these studies might use totally different methodologies (and motivations) to assess the economic effects of GM maize. In addition, results are potentially biased because studies might differ in their focus on potential or realized yield levels, their use of different baselines for comparisons and other background conditions. Most studies and surveys capture information only over one or perhaps a few growing seasons, longer-term market responses to the introduction of GM maize are not reflected in the analysis.

\section{Results and Discussion}

\subsection{Competition for Land and Water}

The combined effect of the Green Revolution has allowed world food production to double in the past 50 years. From 1960 to present the human population has more than doubled to reach seven billion people (Figure 1).

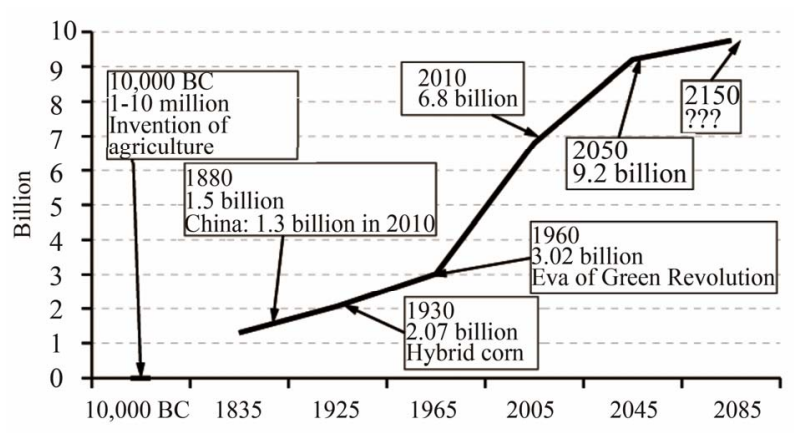

Figure 1. World population growth [1].

The 7 billion world population is projected to increase by $30 \%$ to 9.2 billion by 2050 . This increased population density, coupled with changes in dietary habits in developing countries towards high quality food (e.g. greater consumption of meat and milk products) and the increasing use of grains for livestock feed, is projected to increase demand for food production increase by $70 \%$ by 2050, compared with average 2005-2007 levels. At the same time the increase in arable land between 2005 and 2050 will be just $5 \%$ [1].

Helping farmers lose less of their crops will be a key factor in promoting food security but even in the poorest countries those rural farmers aspire to more than selfsufficiency. The reduction of current yield losses caused by pests, pathogens and weeds are major challenges to agricultural production. Globally, an average of $35 \%$ of potential crop yield is lost to pre-harvest pests [2]. In addition to the pre-harvest losses transport, pre-processing, storage, processing, packaging, marketing and plate waste losses are relatively high. If there is going to be enough food at affordable prices for the global population, we may also have to change our food habits and decrease food waste. Food waste in the field pre-processing (broken grains, excessive dehulling), transport (spillage, leakage), storage (insects, bacteria) and processing and packaging (excessive peeling, trimming and inefficiency) goes up to $10 \%-15 \%$ in quantity and $25 \%-50 \%$ in value (quality). Marketing (retailing) and plate (by consumers and retailers) waste adds another $5 \%-30 \%$ in developed and $2 \%-20 \%$ in developing countries to the losses in the food chain (Figure 2). Roughly one-third of the edible parts of food produced for human consumption, gets lost or wasted globally. Food losses in industrialized countries are as high as in developing countries, but in developing countries more than $40 \%$ of the food losses occur at post harvest and processing levels, while in industrialized countries, more than $40 \%$ of the food losses occur at retail and consumer levels [4]. We can save also water by reducing losses in the food chain.

Land use change is not a new concept but is something that has been taking place since the beginning of civilization and continues to do so. In this context, agri- 


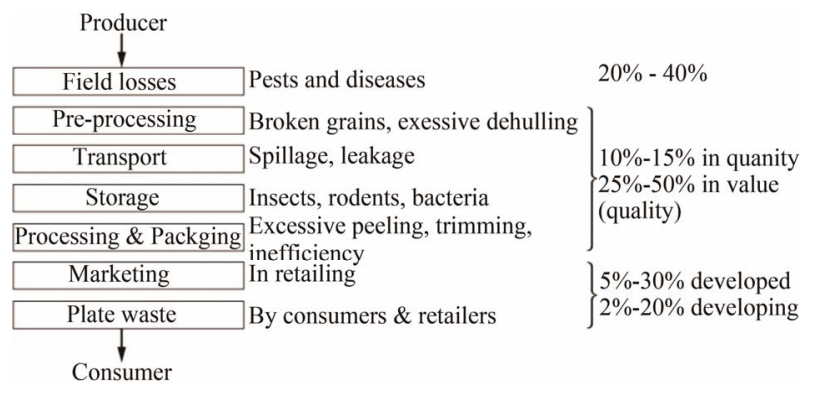

Figure 2. Losses along the food chain [3].

culture has always been an important driver, so far mostly for food and feed production. A growing world population and a changing diet have led to continuously expanding areas of agricultural land, despite parallel increases in yields from existing cropland. In addition, cropland is lost due to erosion through chemical and physical degradation, which further increases the requirement for new agricultural land. On the other hand cultivated land is tightening due to population growth and accelerated urbanization and motorization ${ }^{1}$, changes in lifestyles, falling water tables and diversion of irrigated water towards the cities [5].

The land surface of our planet is equal to 13.4 billion hectares of which $38 \%$ is given over to agriculture and $30 \%$ to forest [6]. The rest of the total is rounded out through a combination of man-made infrastructure, inland water systems, and land that is unsuited for agriculture and forestry (desert, rocks etc.). Of the 5 billion hectares of land used for agricultural purposes worldwide around one-third is suited to annual or permanent crops whereas just over two-thirds are allocated to permanent meadows or pasture. Just 1.6 billion hectares are used for crop production (arable land and land under permanent crops).

Over the last 50 years, land and water management has met rapidly rising demands for food and fibre. In particular, input-intensive, mechanized agriculture and irrigation have contributed to rapid increases in productivity. The world's agricultural production has grown between 2.5 and 3 times over the period while the cultivated area has grown only by $12 \%$ as a result of two opposite trends: an increase of 227 million ha in developing countries, and a decline of 40 million ha in developed countries. More than $40 \%$ of the increase in food production came from irrigated areas, which have doubled in area over the same period, accounting for $15 \%$ of all arable land. In the same period, the cultivated area of land per person gradually declined from 0.45 to less than 0.23 ha indicating that the largest contribution to increases in agricultural output will most likely come from intensification of production on existing agricultural land [6].

\footnotetext{
${ }^{1}$ An estimated 40,000 ha of land are needed for basic living space for every 1 million people added and 20,000 ha of land are needed for every 1 million vehicles added.
}

Future agricultural production will have to rise faster than population growth largely on existing agricultural land. Improvements will thus have to come from sustainable intensification that makes effective use of land and water resources as well as not causing them harm. Regarding yield improvements, there seems to be a large theoretical potential for yield improvements throughout the world, especially in the developing countries, but there are still major uncertainties as to what proportion of this potential can be harvested. The increase in food demand is met to some extent by an increase of agricultural yields. Crop yields would continue to grow, but at a slower rate than in the past. On average, annual growth would be about half that of the historical period: $0.8 \%$ per annum from $2005 / 2007$ to 2050 , against $1.7 \%$ per annum from 1961 to 2007 . Nevertheless, agricultural production would still need to increase by $70 \%$ by 2050 to cope with a $30 \%$ increase in world population. This translates into additional production of 1 billion tons of cereals and 200 million tons of meat a year by 2050 (compared with production in $2005 / 2007$ ). In addition to yield growth there will also be a slow expansion of agricultural land. Arable land would expand by 70 million ha $(5 \%)$, an expansion of about 120 million ha in developing countries being offset by a decline of 50 million ha in developed countries. Much of the suitable land not yet in use is concentrated in a few countries in Latin America and sub-Saharan Africa, not necessarily in Asia (with some $60 \%$ of the world's population) where it is most needed, and much is suitable for growing only a few crops, not necessarily those for which the demand is highest [6]. Future yield increases on lands currently supporting high production levels must come from continued yield enhancing genetic modifications. It is quite conceivable that genetics will face greater challenges in fostering higher yields in significant areas that already are highly productive.

\subsection{Maize Production and Trade Flows}

World grain production (including rice) has remained stable over the recent years and fluctuated between 2.2 2.3 billion tons [6]. On the supply side, there was a time when grain production was on the rise almost everywhere. Today in a number of countries, grain harvests are shrinking because of aquifer depletion and severe soil erosion. Even several advanced countries have run out of new technology to raise land productivity. Sources of growth on the demand side are the population growth, the increasing number of people moving up the food chain consuming more grain-intensive livestock products, and the massive conversion of grain to fuel ethanol.

The most important grain and feed is maize with a world production of around 820 - 860 million tons a year followed by wheat (650 - 700 million tons a year) and 
rice (450 million tons/year). The uses of maize are myriad, since every part of the plant can be utilized. In addition to its primary use as a feed grain, corn byproducts include corn oil, cornstarch, corn syrup, lactic acid and vitamin-C, corncob fuels, automobile paint, ethanol fuels, plastics, tires, chewing gum, foot powder, surgical dressings and bourbon whiskey, to mention only a few of thousands of uses.

Maize breeding in prehistory resulted in large plants producing large ears. Modern breeding began with individuals who selected highly productive varieties in their fields and then sold seed to other farmers. These early efforts were based on mass selection. Later breeding efforts included ear to row selection, hybrids made from selected inbred lines, and the highly successful double cross hybrids using 4 inbred lines. By the 1930s, companies such as Pioneer devoted to production of hybrid maize had begun to influence long term development. Prior to about 1930 open pollinated corn varieties were used exclusively. At the present time hybrid seed is used on essentially all land planted to corn. Genetic improvement has not only contributed to yield increases but also to other desirable plant components such as resistance to lodging and tolerance to increased plant populations, insects, and diseases. More recently, value added traits have been introduced such as high oil content.

From the beginning of records in the 1880s, through the mid 1930s, there was no significant increase in the average corn yield. Yields during the 1920s and 1930s in the US were no higher than those produced as an average in the late 1800s. It was not until the vast technological advances in the early 1940s that corn yields started to show significant yield increases. Hybrid seeds have been largely responsible for remarkable increases in average corn yields. Corn grain yields in the US have increased from an average of $1.5-2.0$ tons per hectare in 1900 to about 9 - 10 tons per hectare in 2010. From 1940 to 1980 , the biologic technology factor of genetic improvement contributed about $59 \%$ of the unit area production of corn in the US [7].

Maize production has increased from 200 million tons in 1960 to over 800 million tons in 2011. The United States grows about $40 \%$ of the maize world production. Other major maize producing countries include China, the EU, Brazil, Mexico, India and Argentina. The United States is not only the world's top maize producer, but also the top exporter. On average, about $15 \%$ of US corn is exported. The United States, Argentina and Brazil are the world's three largest maize exporters with around $80 \%$ share of world maize trade. The US share of global maize trade is around $45 \%-50 \%$, Argentina with a small domestic market is the world's second largest maize exporter. In the last several years, Brazil has targeted the EU's demand for non-genetically modified maize. This marketing situation is assumed to decline as Brazil continues to expand the planting of GM maize varieties (Table 1).

$11 \%$ of global maize production was internationally traded in 2010. Within the leading exporting nations, the biotech maize growers of the US, Argentina, Brazil, South Africa and Canada are important players. The share of biotech maize in global trade accounted for $82 \%$ of global production [9].

\subsection{Global Status of Commercialized GM Crops}

The produce of GM plants and its derivatives (whether or not mixed with non-GM stocks) account for, year on year, a greater volume of international trade and constitute an increasing share of the world's feed and food chains. The International Service for the Acquisition of Agri-biotech Applications (ISAAA) estimated that in 2011 in 29 countries worldwide representing $60 \%$ of world's population some 17 million farmers planted commercialised GM varieties. More than half the world's population, $60 \%$ or around 4 billion people, live in the 29 countries planting biotech crops. The global area planted to GM crop varieties amounted to 160 million hectares which represented $10 \%-11 \%$ of global cropland. Stacked traits occupied about $25 \%$ of the global 160 million hectares of biotech crops. Biotech crops are accepted for import for food and feed use and for release into the environment in 60 countries and regions: in 29 countries and regions for planting and in 31 countries and regions for importing and exporting countries and regions like the USA, Japan, Canada, Mexico, South Korea, Australia, the Philippines, New Zealand, the European Union, and Taiwan. The United

Table 1. Global maize trade, million tons [8].

\begin{tabular}{ccc}
\hline & $\mathbf{2 0 1 0} / \mathbf{2 0 1 1}$ & $\mathbf{2 0 1 1}^{2012^{*}}$ \\
\hline Global trade & 90.5 & 94.9 \\
Exporters & 46.6 & 43.2 \\
Argentina & 15.0 & 14.0 \\
Brazil & 9.0 & 9.0 \\
Ukraine & 5.0 & 14.0 \\
South Africa & 2.5 & 2.0 \\
& Importers & 16.1 \\
Japan & 15.7 & 9.8 \\
Mexicó & 8.3 & 6.0 \\
South Korea & 8.1 & 4.0 \\
Egypt & 5.8 &
\end{tabular}


States is the leading producer of GM crops accounting for 69 million hectares of the total GM crop area. Brazil is second, producing GM crops on 30 million hectares. Argentina had about 24 million, India and Canada over 10 million hectares of GMO area in 2011. Six EU member states (Spain, Portugal, Czech Republic, Poland, Slovakia and Romania) planted record 114,490 hectares of Bt maize in 2011, with Spain growing $85 \%$ of the total in the EU with a record adoption rate of $28 \%$. Bt maize hectarage increased in the three largest Bt maize countries: Spain, Portugal and the Czech Republic [9].

Almost all of the global biotech crop area consists of soybeans, maize, cotton and canola. In 2011, GM soybeans accounted for the largest share (47\%), followed by maize (32\%), cotton (15\%) and canola (5\%). In terms of the share of total global plantings to these four crops, biotech traits accounted for $75 \%$ of soybean plantings. For the other three main crops, the biotech shares in 2011 were $82 \%$ for cotton, $32 \%$ for maize and $26 \%$ for canola. A total of 1045 approvals have been granted for 196 events for 25 crops. The adoption rate of GM maize was $90 \%$ in the USA, $65 \%$ in Argentina and the USA and $50 \%$ for the summer maize and $65 \%$ for the winter maize in Brazil. These three countries are the world's three largest maize exporters with above $80 \%$ share of world maize trade. Maize has the most events approved, out of the 65 approvals (EU27 counted as 1 approval only) insect resistant maize MON810 tops the list with 23 approvals followed by herbicide tolerant maize NK603 with 22 approvals each [9].

\subsection{Costs and Benefits of GM Maize}

Green biotechnology, particularly the development of genetically modified crops, has been one of the major technological innovations in global agriculture of the last decades. Since its first commercial application in 1996, the the share of total global plantings to GM maize has increased to $32 \%$ in 2011 [9]. The effect of a widespread application of GM maize (and other GM crops) on sustainable development has been the subject of controversial discussions ranging from food production and health issues to impacts on ecosystems and the environment. As a result, the literature on the impacts of GM crops is already substantial, especially in terms of the socio-economic impacts on farmers, their families and consumers. The voices on both sides of the debate (pro and anti-GM crops) have pointed to individual studies that support their view and clearly there is much contradiction.

The extra farm income from growing biotech crops, when spent on goods and services, has had a positive multiplying effect on local, regional and national economies. In developing countries, the additional income has enabled more farmers to consistently meet their food subsistence needs and to improve the standards of living of their households. In India and the Philippines, where farmers use biotech IR cotton and maize respectively, their household incomes have typically increased by over $33 \%[10]$.

Although the primary impact of biotech HT technology has been to provide more cost effective (less expensive) and easier weed control versus improving yields from better weed control (relative to weed control obtained from conventional technology), improved weed control has nevertheless occurred, delivering higher yields in some countries (eg, HT corn in Argentina and the Philippines). In global terms, the farm level economic impact of using GM HT technology in maize was \$392.1 million in 2009 ( $72 \%$ of which was in the US). Cumulatively since 1997, the farm income benefit has been (in nominal terms) $\$ 2.23$ billion. Of this, $90 \%$ has been due to cost savings and $10 \%$ to yield gains (from improved weed control relative to the level of weed control achieved by farmers using conventional technology). In terms of the total value of maize production in the main countries using this technology in 2009, the additional farm income generated by the technology is equal to a value added equivalent of $0.3 \%$ of global maize production [10].

In global terms, the farm level impact of using GM IR maize was $\$ 2.6$ billion in 2009. Cumulatively since 1996 , the benefit has been (in nominal terms) $\$ 11.16$ billion. This farm income gain has mostly derived from improved yields (less pest damage) although in some countries farmers have derived a net cost saving associated with reduced expenditure on insecticides. In terms of the total value of maize production from the countries growing GM IR maize in 2009, the additional farm income generated by the technology is equal to a value added equivalent of $3.8 \%$. Relative to the value of global maize production in 2008, the farm income benefit added the equivalent of $2.3 \%$ [10].

The biotech IR traits, used in the corn sectors, have targeted major pests and have accounted for $99 \%$ of the additional corn production. These pests, persistent in many parts of the world, significantly reduce yield and crop quality, unless crop protection practices are employed. The biotech IR traits have delivered positive yield impacts in user countries when compared to average yields derived from crops using conventional technology (such as application of insecticides and seed treatments). Since 1996, the average yield impact across the total area planted to these traits over the 14-year period has been +7.1 percent for corn traits. GM rootworm resistant (CRW) maize has been planted commercially in the US since 2003. In 2009, there were 16.5 million ha of CRW maize ( $51 \%$ of the total US crop). The main farm income impact has been higher yields of about 5\% relative to conventional corn. The impact on average costs of production has been $+\$ 12 /$ ha to $-\$ 10 /$ ha (based on an ave- 
rage cost of the technology of $\$ 25 /$ ha - $\$ 42 /$ ha and an insecticide cost saving of $\$ 32 / \mathrm{ha}-\$ 37 / \mathrm{ha})$. As a result, the net impact on farm profitability has been $+\$ 24 /$ ha to $+\$ 87 /$ ha. At the national level, farm incomes increased by $\$ 4$ million in 2003, rising to $\$ 1.29$ billion in 2009 . Cumulatively since 2003, the total farm income gain from the use of CRW technology in the US maize crop has been $+\$ 3.3$ billion. CRW cultivars were also planted commercially for the first time in 2004 in Canada. In 2004, the area planted to CRW resistant varieties was 418,000 ha. Based on US costs, insecticide cost savings and yield impacts, this has resulted in additional income at the national level of $\$ 26.8$ million in 2008 (cumulative total since 2004 of $\$ 41$ million). At the global level, the extra farm income derived from biotech CRW maize use since 2003 has been $\$ 3.36$ billion production [10].

However, there is a lack of available publications for developing countries. In particular, Brazil and Argentina (as well as Mexico) are relatively under-represented (given the large area under GM maize in these countries) in the database suggesting that there are few published accounts for GM performance in English in those countries [1113]. However, there is a lack of publications on farmlevel GM maize benefits in Europe with the exception of Spain due to the small adoption rates of GM maize in Europe [14]). Moreover, the focus of European research related to GM maize is rather on coexistence, public acceptance, or environmental impacts than farm-level socioeconomic benefits [15-17]. Most European analysis on GM maize has been published in form of reports and conference papers, and these are not so readily accessible. Moreover, there is a general lack of available sources for farm-level benefits of $\mathrm{Bt}$ maize for developed countries, for example, for the USA [18].

The use of individual studies is furthermore hampered by the fact that these studies might use totally different methodologies (and motivations) to assess the economic effects of GM maize. For instance, such assessment might be based on impact studies using field trials or surveys that have been conducted by public research institutions or private companies [19]. For example, a sensitivity analysis on the general study type (comparing for instance field trials and surveys) and the study conductor using the database revealed differences within these items, but the problem is that this factor is often coofounded with others such as the crop and country. It is rare to find a situation where a GM maize grown in one country has been the subject of a range of different yet replicated methodologies. In addition, results are potentially biased because studies might differ in their focus on potential or realized yield levels, their use of different baselines for comparisons and other background conditions.

The analysis of trends of GM maize effects over time did not reveal significant changes, but most studies and surveys capture information only over one or perhaps a few growing seasons, which are relatively short periods of time to assess the long-term impact of the introduction of a new technology. Thus, long-term effects, particularly with respect to infestation levels, pesticide costs and crop yields, might not be adequately addressed by combining several short-term studies [20].

A paper on farm-level costs and benefits reviews the evidence on the socio-economic impacts of GM Bt maize and analyzes whether there are patterns across space and time [21]. Most data for Bt maize were available for Spain, Germany, South Africa and Argentina. Only limited observations are available for the Czech Republic, France, Poland, Portugal, Romania, and Slovakia. Othe papers focus on on the socio-economic impacts of GM insect resistant (IR) and herbicide tolarent (HT) maize. Moreover, longer-term market responses to the introduction of GM maize are not reflected in the analysis. For instance, land rents might rise with increasing rates of $\mathrm{Bt}$ maize adoption. Thus, economic rents of GM maize for example might increase the welfare of landowner and not necessarily those of the farmers [21].

Seed costs for Bt maize were significantly higher than for conventional maize (in the range of 48\%). Yields, pesticide costs and management and labor costs were not significantly affected by $\mathrm{Bt}$ maize adoption. While no significant interaction was found for yield or pesticide, management and labor costs, a significant interaction effect for seed cost indicates that the mark-up for Bt maize is fading over time. However, it should be noted that this particular result was caused by very low seed costs (i.e., influential observations with a leverage effect) in the year 2007 for some European countries. Most coefficients were insignificant showing that differences between countries explained the vast majority of heterogeneity within the data. The lack of observations for most variables and countries requires a careful interpretation [21].

Even an increasing demand for genetically modified seeds could conceivably increase seed costs for farmers and an increased production due to widespread GM adoption might reduce output prices. Furthermore, farmlevel costs and benefits of GM maize might be highly influenced by governmental regulation and societal acceptance as in many parts of Europe [22,23]. In general, benefits have to be balanced with local public concerns, as public opinion can influence individual famers adoption choices. Moreover, large scale farm structures in the Oderbruch region particularly facilitated the adoption of BT maize due to low costs for compliance with co-existence rules in Germany. In South Africa, yield advantages for Bt maize seem to be more consistent over time and across regions for smallholders as well as large commercial farmers during the growing seasons 2000/2001 to 
2003/2004 as compared to Spain and Germany. However, after three years of dry conditions, low stem borer infestation levels reduced the benefits of $\mathrm{Bt}$ maize [24]. In addition, the risk of resistance of insects and weeds to GM traits and herbicides should be addressed in further research [25]. Compared to conventional crops, GM maize can lead to yield increases and can lead to reductions in the costs of pesticide application, whereas seed costs are usually substantially higher [26].

On a global level no overall large yield effect of $\mathrm{Bt}$ maize (resulting from reduced yield losses) was indicated. In cases where yield increases and the reduction of pesticide inputs outweigh the higher seed costs, farmers receive a higher gross margin by growing GM maize. However, the results also show a heterogeneous pattern with benefits of GM maize adoption being manifested in various ways, depending upon the extant pest management practices in the specific country. The heterogeneous impact patterns (depending on local production conditions) are not exclusively a GM maize specific result, but are rather the rule for agricultural technologies in general. The same mechanisms are at play when progressing from the country to the regional level. Indeed the heterogeneity of study results can be even larger at the regional level. A survey conducted in Spain showed yield effects of $\mathrm{Bt}$ maize adoption that ranged from $-1.3 \%$ in Albacete to $+12.1 \%$ in Zaragoza. The results indicate lower pesticide costs for Bt maize but significant effects were only observed in Spain and Germany. As for yields, pesticide reductions in Spain varied widely between regions of that country. Farmers in Albacete and Zaragoza had 33\% and $37 \%$ of the pesticide costs of conventional maize growers, whereas in Lleida no difference in pesticide cost was observed. Farmers report substantial labor savings $(20 \%$ - 30\%) from using GM crops in reduced application of pesticides or weed management $[27,28]$. However, proof of demand by farmers can be found in the increase in acres planted and the increase in composite seed price indices of between 30 and $100 \%$ for GM maize seeds [28]. The price increase includes the effects of demand and greater value (seed plus insecticide in one package, for example).

The observed economic impacts of GM maize in any place will depend on the yield potential of crop varieties (GM as well as conventional varieties), the pest pressure, general and seasonal dependent climate and weather conditions, as well as government intervention. Several reports have addressed the effects of GM maize on the environment and on human health. However, the effects of agricultural biotechnology at the farm level-that is, from the point of view of the farmer-have received much less attention. Economic effects of GM crop plantings on non-GM producers have not received adequate research. GM crops can affect the input prices and options for both farmers who use feed and food products made with GM ingredients and farmers who have chosen not to grow GM seed or do not have the option available. Livestock producers constitute a large percentage of corn buyers and therefore are major beneficiaries of any downward pressure on crop price due to the adoption of GM crops. Livestock producers also benefit from increased feed safety due to reduced levels of mycotoxins in the grain Adopters of GM crops experience increased worker safety and greater simplicity and flexibility in farm management, benefitting farmers even though the cost of GM seed is higher than non-GM seed [28].

\subsubsection{Social Effect}

Studies found no adverse effects on farmers' economic welfare from the consolidation of market power in the seed industry. However, there has been little research on how increasing market concentration of seed suppliers affects overall yield benefits, crop genetic diversity, seed prices, and farmers' planting decisions and options. Additional concerns are being raised about the lack of farmer input into and knowledge about which seed traits are being developed.

Favorable and unfavorable social impacts exist from the dissemination of genetic-engineering technology. There is no doubt that the strict tolerance levels of GMO contamination represent a serious problem for those preferring the traditional varieties, producers, processors and consumers alike. The impact of GM crops on the markets of conventional crops and animal products is not yet clear, and that further studies are therefore needed in this direction [28].

\subsubsection{Time and Bt Effect}

Coefficient estimates show that there is no significant change in all of the economic performance indicators over time (except for seed costs, showing a slight reduction over time). Increases over time in maize yields were expected, at least for most of the developed world [29]. However, such a trend was not indicated by the results because of the relatively short time period of observations for Bt maize (dataset covers the period 1997-2007).

\subsubsection{Yields}

[30] estimated an average yield advantage of $6.3 \%$ for Spain between 1998 and 2003 and of 10\% from 2004 onwards. However, yield advantages reveal large heterogeneity over regions and time. Highly heterogeneous results depending on region, infestation level and the effectiveness of common pest management practices were also observed in Germany: Whereas most studies show yield increases due to Bt maize adoption others did not find significant yield differences [31]. Another study mentioned pest pressure affected by weather as an important 
determinant in the advantage of Bt maize. Gross margins showed advantages of Bt over conventional maize. Higher seed costs could be offset by higher yields and/or lower pesticide costs. In Spain, the main reason for gross margin differences have been attributed to different yield effects [27,32]. In Germany, Bt maize seems to be most beneficial in the Oderbruch region due to high pest infestation levels. Indeed, the ability to significantly reduce pesticide costs is the main reason for the adoption of $\mathrm{Bt}$ maize for German maize farmers because other available pest control measures did not effectively control pests [32,33].

Grain maize benefit from planting Bt maize are higher yields which have to cover the additional costs. In this research, yield increases were assumed to be $8.7 \%$. This yield increase covers the additional costs from Bt maize planting for all farms and results in a gross margin increase. The profit for Spanish farms is the highest with an average gross margin surplus of $€ 185$ per ha, followed by the Italian farms with $€ 132$ per ha and German farms with $€ 66$ per ha. The breakeven point for adopting $\mathrm{Bt}$ maize is a yield increase of $1.5 \%$ in Spain, $2.8 \%$ in Italy and $3.3 \%$ in Germany. Silage maize benefit for farmers is mainly the healthier crop due to lower mycotoxin contamination. This quality aspect is also of high importance for grain maize. However, the study shows the breakeven points for silage maize are reached at a yield increase levels of $2.9 \%$ for Italy and $3.6 \%$ for Germany on average among the case study farms. Coexistence measures can also cause costs to the farms. These costs have to be at least covered by the profit resulting from Bt maize planting. The reported results suggest this to be possible [34].

\subsubsection{Costs}

The main findings of the case study on the comparison of $\mathrm{Bt}$ and Non-Bt maize cultivation claims that farmers gain from Bt-maize [34]. In this research study five Spanish, five Italian and ten German farms were chosen to conduct case studies and examine economic effects of $\mathrm{Bt}$ maize cultivation. Spain is the only country of these three, where Bt maize had been planted in 2010. In Italy Bt maize planting has never been allowed and in Germany it had been allowed until 2009. Therefore data from Bt maize in Spain and conventional maize in Italy and Germany from the year 2010 were gathered. All surveyed Spanish farms cultivated Bt maize and did not use insecticides for the European Corn Borer (ECB). Four Italian farms and only three of the German farms used insecticide treatments for ECB. Insecticides are either applied with own machinery or by contractors. The average spraying cost are $€ 77$ per ha for the Italian and $€ 57$ per ha for the German farms. The farmers who did not spray insecticides valued the costs for spraying higher than the benefit. Insecticide costs for case study farms to increase yields by $1 \%$ are $€ 11$ compared to Bt maize, which costs $€ 4$ per $1 \%$. Costs of Bt maize cultivation are the additional seed costs. These were assumed to be $€ 23$ per ha grains multiplied with the amount of seed used per ha. Average additional costs were calculated to be about $€ 35$ to $€ 38$ per ha for Spanish and Italian farms and up to $€ 44$ per ha for German farms due to a higher amount of grains used per ha.

In South Africa, the main advantage of $\mathrm{Bt}$ maize for some farmers was higher yields, while for others it was higher quality of the produce [35]. However, in growing seasons with low pest pressure, Bt maize growers were worse off than conventional farmers as Bt does not provide yield benefits per se and the seed costs are higher [35]. Quality advantages of $\mathrm{Bt}$ maize have also been observed in Germany because of reduced mycotoxin content [35].

In South Africa, reduced labor and fuel costs were observed for large commercial farmers because less pesticide applications were needed and less time was spent scouting fields for pests. This finding is supported by the observation that the reduction of pesticide costs in South Africa was highest in irrigated areas where the moist conditions particularly favor insect growth and reproduction [35]. However, for example, if pest management was already well established before the adoption of Bt maize then any yield benefits which arise from growing such insect-resistant GM varieties may be rather low (e.g., the USA and Australia). These countries, however, benefit most from reduced pesticide costs. In countries with poorer pesticide or herbicide management (e.g., India for $\mathrm{Bt}$ cotton), yield advantages were the major benefit of GM crop adoption, as yield losses can substantially be reduced. However, benefits of GM maize might differ substantially between years, in particular due to large variability of infestation levels and/or weather [35]. Thus, farmers' advantages of GM crop adoption appear in various ways, depending on the pest management practices in the specific country. Hence results from different locally conducted studies often do not show clear and consistent trends, thereby allowing those at either end of the GM debate to select studies that support their own view.

For South Africa, seed cost differentials are dependent on the seed company but no seed cost data are available. Whereas some studies show Bt seeds being offered free of charge by a seed company as smallholders were not able to pay mark-ups for Bt seed due to financial constraints [35]. There were significantly higher seed costs for Bt than for conventional maize in Spain, Germany and Argentina. Bt mark-ups in seed cost ranged from $10 \%$ (Spain) to 36\% (Argentina). In Spain, seed costs varied between regions because of the divergent pricing policies of seed suppliers, the bargaining power of farm- 
ers and the potential for price discrimination between farmers [36]. In general, seed prices were lower in regions where yield benefits from GM crops were low. The data for Germany showed almost $17 \%$ higher seed costs for Bt than for conventional maize, however, in Spain seed prices vary with region and infestation level (i.e., potential demand). A study conducted in Saxony (Germany) showed that seed costs for Bt seed were low due to discounts on $\mathrm{Bt}$ seed and reduced planting densities for Bt maize [32,36]. For small farmers, in particular, this labor savings can be monetized by using this time for off-farm employment, thereby further amplifying the indirect benefits of planting GM crops [37]. For Germany, increased management and labor costs were indicated due to the adoption of Bt maize. This result represented the additional labor needed to clean the machinery used for Bt maize (due to legal restrictions on GM crops). In Spain, increased management flexibility and convenience, reductions in contractor costs for spraying and reduced production risk were reported $[32,38]$.

\subsubsection{Economic Benefit}

Despite growing evidence of economic benefits, contradictory reports continue to emerge regarding the overall economic impacts of GM crops. These discrepancies occur in large part due to differences in how pesticide use is recorded (for example, by total volume or by active ingredient volume) and similar experimental issues, although special literatures found substantial variation in performance and yield across different farms and different crops. Given the variability in assessing crop performance, the best indicator of the farm scale benefits of GM crops is simply the continued use and increased adoption by farmers worldwide.

Economic benefits (derived from higher yields and/or reduced costs depending on the agronomic trait), production efficiency and flexibility, enhanced weed control and the facilitation of conservation tillage were pointed out as drivers to explain the rapid adoption of GM HT crops. Farmers who have adopted GM crops have experienced lower costs of production and obtained higher yields in many cases because of more cost-effective weed control and reduced losses from insect pests. The application of biotechnology, the cultivation of GM plants had important economic benefits in comparison with conventional varieties used in traditional farming, even if they are not always universal, and may diminish over time. The economic benefits resulting from the application of biotech seeds and the associated production technologies usually outweigh the additional costs. In the case of GM plants weed control is more flexible and cost-effective, and pest-related yield loss is usually lower compared to traditional varieties, so the production cost per tonne of harvested crop is lower. The effect GM crops have had on prices received by farmers for corn is not completely understood. Studies suggest that the adoption of GM crops with productivity increases puts downward pressure on the market prices of the crops. However, early adopters benefit from higher yields or lower production costs more than nonadopters even with lower prices. The gains tend to dissipate as the number of adopters increases, holding technological progress constant. However, the extent to which GM crop adoption in developing countries will influence productivity and prices, and therefore US farm incomes, is not completely understood $[28,39]$.

With regard to yield improvement, some crop-trait combinations such as $\mathrm{Bt}$ maize is reported to produce higher yields [40,41]. For other crop-trait combinations such as GM HT maize, no significant differences were found in terms of yields between GM HT and conventional varieties. While yields seem to be equal, net income gains from GM HT crops were reported. These income gains are due to the potential cost reduction of GM HT crops with respect to the conventional alternative through lower expenditures on herbicides, labour, machinery and fuel $[42,43]$.

\subsubsection{Environmental Benefits}

Several authors have reported environmental benefits associated with the adoption of GM HT crops, such as the substitution of selective herbicides (usually harmful for the environment) for less toxic broad-spectrum herbicides, or fuel savings associated with less spray runs and conservation tillage practices. However, there are also potential environmental risks associated with weed management changes related to HT crops. Impacts on biodiversity, the selection of resistant weeds by intensive herbicide applications are some of the potential risks, or the appearance of HT volunteers. Biotech crops have generally less impact on the environment than conventional crops. The spread of herbicide-tolerant GM corn can facilitate the transition to conservation tillage methods which reduce soil erosion, and increase soil carbon and nitrogen content. The spreading of Bt corn is accompanied by a decline in the use of pesticides, which benefits the environment and wildlife. Gene flow to wild or weedy relatives has not been a concern to date The potential risks presented by gene flow may increase as GM traits are introduced into more crops $[28,44]$. All these aspects, economic, environmental and technical, play a role in farmers' decision to adopt the new technology. If GM technology had not been available to the 14 million farmers using the technology in 2009, maintaining global production at the 2009 levels would have required additional plantings of 5.6 million ha of corn. This total area requirement is equivalent to about $4 \%$ of the global harveted corn area $[10,44]$. 
Knowledge gained over the past 15 years that GM crops have been grown commercially indicates that the impacts on biodiversity are positive on balance. By increasing yields, decreasing insecticide use, increasing use of more environmentally friendly herbicides, and facilitating adoption of conservation tillage, GM crops have contributed to increasing agricultural sustainability. In addition to the potential benefits of expanded adoption of current technology, several pipeline technologies offer additional promise of alleviating the impacts of agriculture on biodiversity. Technologies such as drought tolerance and salinity tolerance would alleviate the pressure to convert high biodiversity areas into agricultural use by enabling crop production on suboptimal soils. The technology has particular relevance for areas like sub-Saharan Africa, where drought is a common occurrence and access to irrigation is limited. Salt tolerance addresses the increasing problem of saltwater encroachment on freshwater resources. Nitrogen use efficiency technology is also under development, which can reduce run-off of nitrogen fertilizer into surface waters. The technology promises to decrease the use of fertilizers while maintaining yields, or increase yields achievable with reduced fertilizer rates where access to fertilizer inputs is limited. In the maize sector, herbicide and insecticide use decreased by 176.7 million $\mathrm{kg}$ and the associated environmental impact of pesticide use on this crop area decreased, due to a combination of reduced insecticide use $(34.8 \%)$ and a switch to more environmentally benign herbicides $(10.5 \%)$. This highlights the switch in GM maize to active ingredients with a more environmentally benign profile than the ones generally used on conventional crops. However, the contribution to reduced levels of carbon sequestration arising from the adoption of GM HT maize is likely to have been marginal but no assessments are presented. Limited analysis of the possible contribution to reduced level of carbon sequestration from the adoption of GM IR maize (via fewer insecticide spray runs) and the adoption of Corn Rootworm Resistance (CRW) maize is presented. This is because the impact of using these technologies on carbon sequestration is likely to have been small $[10,45]$.

\subsubsection{Biocontrol Services}

Over the past 16 years, vast plantings of transgenic crops producing insecticidal proteins from the bacterium $B a$ cillus thuringiensis $(\mathrm{Bt})$ have helped to control several major insect pests and reduce the need for insecticide sprays. Because broad-spectrum insecticides kill arthropod natural enemies that provide biological control of pests, the decrease in use of insecticide sprays associated with Bt crops could enhance biocontrol services. Field studies indicated that $\mathrm{Bt}$ crops protected natural enemies in comparison with non-Bt crops, which rely on con- ventional insecticides. Decreasing insecticide application, through widespread Bt cotton plantings, sustained generalist predators and helped to suppress aphid populations in this crop. In addition, the predators might provide additional biocontrol services spilling over from Bt cotton fields onto neighbouring crops (maize, peanut and soybean). This work extends results from general studies evaluating ecological effects of Bt crops by demonstrating that such crops can promote biocontrol services in agricultural landscapes $[46,47]$. However, this hypothesis has not been tested in terms of long-term landscape-level impacts.

A recently published study provides a comprehensive, long-term and large-scale assessment of the possible ecological and agricultural effects of transgenic crops by demonstrating a marked increase in generalist predator population levels and associated biocontrol services linked to decreased insecticide use owing to the widespread adoption of the Bt crop [48]. Large-scale surveys were conducted in six provinces in northern China (36 locations, 10 - 20 fields per location) to evaluate the impact of insecticide applications on the abundance of predators and aphids in cotton fields. First, the relationship between predator abundance and insecticide use during the period 1990-2010 (that is, including the period before and during the widespread adoption of Bt cotton by farmers) was tested, and second, how cotton aphid density was related to predator abundance during the same period. On the basis of data from 1990 to 2010, a marked increase in abundance of three types of generalist arthropod predators (ladybirds, lacewings and spiders) and a decreased abundance of aphid pests associated with widespread adoption of Bt cotton with reduced insecticide sprays was demonstrated.

Broadly speaking, the deployment of Bt crops may favour biocontrol services and enhance economic benefits not only in Bt crop fields but also in the whole agricultural landscape. Biocontrol services are potentially provided by $\mathrm{Bt}$ crops throughout the agricultural landscape offering new options in developing conservation biological control measures at the landscape level.

\section{Conclusions}

Land use change has been taking place since the beginning of civilization and agriculture has always been an important driver, so far mostly for food and feed production. Besides competition with food and feed, increased use of biomass also has its effects on land use. A growing world population and a changing diet have led to continuously expanding areas of agricultural land, despite parallel increases in yields from existing cropland. On the other hand cultivated land is tightening due to population growth and accelerated urbanization and motorization, changes in lifestyles, falling water tables and di- 
version of irrigated water towards the cities. Land use for food and feed are typically determined by global diet and agricultural yield improvements. Crop yields would continue to grow, but at a slower rate than in the past. Yield growth will play an important role as only a slow expansion of agricultural land is expected.

World grain production of $2.2-2.3$ billion tons a year has not increased in recent years. In a number of countries grain production is shrinking (aquifer depletion and soil erosion) and developed countries have run out of new technology to raise land productivity. Sources of growth on the demand side are the population growth, the changing diet and the conversion of grain to fuel ethanol.

The most important grain and feed is maize with a world production of around 820 - 860 million tons. Modern breeding began with individuals who selected highly productive varieties in their fields and then sold seed to other farmers. These early efforts were based on mass selection. By the 1930s, companies such as Pioneer devoted to production of hybrid maize had begun to influence long term development. At the present time hybrid seed is used on essentially all land planted to corn. Genetic improvement has not only contributed to yield increases but also to other desirable plant components such as resistance to lodging and tolerance to increased plant populations, insects, and diseases. More recently, value added traits have been introduced such as high oil content. Maize production has increased from 200 million tons in 1960 to over 800 million tons in 2011 but has not changed very much recently. The United States, Argentina and Brazil are the world's three largest maize exporters with around $80 \%$ share of world maize trade. About $11 \%$ of global maize production was internationally traded in 2010 and the share of biotech maize in global trade accounted for $82 \%$ of global production. Maize exporting countries continue to expand the planting of GM maize varieties.

The claim by GM critics that yield increases over conventional varieties are not there, thus undermining their economic benefits, is too simplistic. The economic gains are not necessarily in direct yield gains, they come from easier agronomy, better protection from insects, lower input costs etc. The commercial pipeline suggests that product quality traits will be increasingly prominent if seed companies are going to maintain decent margins from the technology leading even to higher economic benefits of GM crops. The results support the contention that the adoption of GM maize leads on average to a higher economic performance, i.e., benefits, for farmers than conventional (non-GM) crops. An important finding of the analysis is that the kind and magnitude of benefits are heterogeneous across crops, traits, countries and regions.
The reviews suggest that the overall assessment of farm-level costs and benefits of GM maize has severe limitations. Published data are skewed towards some developing countries, thereby increasing their representation compared to the globally more important agricultural producing countries in a combined analysis. Moreover, such overall (or general) assessment often combines data sources that rely on totally different methodologies and assumptions and are conducted with different purposes. Furthermore, a summary of several (often) shortterm individual studies may not necessarily capture longterm environmental and economic effects and trends.

Though yield increases are significant for specific countries, no general increases of crop yields for analyzed countries were observed due to the adoption of GM maize. This is due to the fact that insect and herbicide resistant traits are not designed to increase crop yield potential. Rather, they are designed to facilitate crop management and yields are indirectly affected through reducing the risk of losses via pest damage. These currently used traits will not allow GM maize to overcome other constraints such as poor soil fertility, salinization or lack of water, although of course the GM industry is working on addressing those characteristics amongst others. However, even then there are key issues of distribution and global market inequalities to consider.

Hence, GM maize by itself cannot address poverty or resolve global food imbalances. Nonetheless, GM maize is a potential tool to increase farmers' income and thus might contribute to poverty reduction and sustainable social and rural economic development, especially in developing countries. However, while the literature on the economic impact of GM crops has grown in recent years there is still a need for more comparative studies across space and time in order to pin down these impacts and allow for a better assessment of the contribution that this technology can make to sustainable development.

The country specific analysis support the existence of higher seed costs for $\mathrm{Bt}$ than for conventional maize. Moreover, some evidence is provided that pesticide costs are lower for Bt maize, whereas yield levels are only slightly higher. The results suggest a large regional heterogeneity of the effects of Bt maize within countries, primarily as a result of different infestation levels and commonly used pest control measures. Regional and seasonal variation also appears to be prevalent for Bt maize performance.

Furthermore, it is important to address concerns about the development of benefits over time. In particular, resistance, secondary pests and the growing market power of seed suppliers could conceivably increase adoption costs and reduce potential benefits of GM crops over time. However, the economic and agronomic consequences of the resistance developed by certain insects to $\mathrm{Bt}$ 
crops can be considered modest at present.

Biotech crops have generally less impact on the environment than conventional crops. By increasing yields, decreasing insecticide use, increasing use of more environmentally friendly herbicides, and facilitating adoption of conservation tillage, GM crops have contributed to increasing agricultural sustainability. Largescale surveys were conducted to evaluate the impact of insecticide applications on the abundance of predators and aphids in cotton fields. On the basis of data from 1990 to 2010, a marked increase in abundance of three types of generalist arthropod predators and a decreased abundance of aphid pests associated with widespread adoption of Bt cotton with reduced insecticide sprays was demonstrated. The deployment of $\mathrm{Bt}$ crops may favour biocontrol services and enhance economic benefits not only in Bt crop fields but also in the whole agricultural landscape.

It is important to note that most of the studies did not include evidence other than farm-level economic effects. Thus, more macro-effects of growing GM maize on the environment and social welfare, as well as indirect effects of the cultivation of GM maize and its possible effects on health and biodiversity, are not considered.

\section{REFERENCES}

[1] FAO, "Looking Ahead in World Food and Agriculture: Perspectives to 2050," Agricultural Development Economics Division Economic and Social Development Department Food and Agriculture Organization of the United Nations, 2011, p. 539.

http://www.fao.org/docrep/014/i2280e/i2280e.pdf

[2] E. C. Oerke, "Crop Losses to Pests," Journal of Agricultural Science, Vol. 144, No. 1, 2006, pp. 31-43. doi:10.1017/S0021859605005708

[3] IWMI, "Water for Food, Water for Life: A Comprehensive Assessment of Water Managementin Agriculture," Earthscan, London, 2007.

[4] J. Gustavsson, C. Cederberg, U. Sonesson, R. van Otterdijk and A. Meybeck, "Global Food Losses and Food Wastes-Extent, Causes and Prevention," FAO, Rome, 2011.

http://www.fao.org/fileadmin/user_upload/ags/publication s/GFL_web.pdf

[5] The Earth Institute, "The Growing Urbanization of the World," Columbia University, New York, 2005.

[6] FAO, "The State of the World's Land and Water Resources for Food and Agriculture. Summary Report," FAO, Rome, 2011.

http://www.fao.org/nr/water/docs/Solaw_ex_summ_web_ en.pdf

[7] L. Gibson and G. Benson, "Origin, History, and Uses of Corn (Zea mays)," Iowa State University, 2002. http://www.agron.iastate.edu/courses/agron212/readings/c orn_history.htm

[8] Toepfer International, "The EU Feedstuffs Market," Toe- pfer International GmbH, Market Review, Hamburg, 2010.

[9] C. James, "Global Status of Commercialized Biotech/GM Crops: 2011," The International Service for the Acquisition of Agri-Biotech Applications (ISAAA), 2012. http://www.isaaa.org/resources/publications/briefs/43/exe cutivesummary/default.asp

[10] G. Brookes and P. Barfoot, "GM Crops: Global SocioEconomic and Environmental Impacts 1996-2009," PG Economics Ltd., Dorchester, 2011.

[11] E. Contini, M. J. A. Sampaio and A. F. D. Avila, "The Lack of Clear GMO Regulation: Its Impact on Researchers and Farmers in Brazil," International Journal of Biotechnology, Vol. 7, No. 1-3, 2005, pp. 29-45.

[12] M. Smale, P. Zambrano, J. Falck-Zepeda, G. Gruère and I. Matuschke, "The Economic Impact of Transgenic Crops in Developing Countries: A Note on the Methods," International Journal of Biotechnology, Vol. 10, No. 6, 2008, pp. 519-551. doi:10.1504/IJBT.2008.022491

[13] C. Paredes, "Socio-Economic Study of the Adoption of Genetically Modified Crops in Entre Rios, Argentina," Masters Thesis, Purdue University, West Lafayette, 2006, $164 \mathrm{p}$.

[14] M. Maciejczak, "Farm-Level Economic Impact of Bt Maize Cultivation in the European Union. Does GM Technology Reduce or Increase the Risk?" Presented at 108th Seminar of European Association of Agricultural Econonmists on Income Stabilisation in a Changing Agricultural World: Policy and Tools, Warsaw, 8-9 February 2008.

[15] G. Brookes, "The Farm-Level Impact of Herbicide-Tolerant Soybeans in Romania," AgBioForum, Vol. 8, No. 4, 2005, pp. 235-241.

[16] G. Brookes, "The Benefits of Adopting Genetically Modified, Insect Resistant (Bt) Maize in the European Union (EU): First Results from 1998-2006 Plantings," PG Economics Ltd., Dorset, 2007.

[17] G. Brookes and A. Aniol, "The Farm Level Impact of Using GM Agronomic Traits in Polish Arable Crops," PG Economics Ltd., Dorset, 2005.

[18] M. Gómez-Barbero and E. Rodrigues-Cerezo, "Economic Impact of Dominant GM Crops Worldwide: A Review," Technical Review Series, Joint Research Center, European Commission, Brussels, 2006.

[19] M. Smale, P. Zambrano and M. Cartel, "Bales and Balance: A Review of the Methods Used to Assess the Economic Impact of Bt Cotton on Farmers in Developing Economics," AgBioForum, Vol. 9, No. 3, 2006, pp. 195212.

[20] J. Carpenter, "Peer-Reviewed Surveys Indicate Positive Impact of Commercialized GM Crops," Nature Biotechnology, Vol. 28, 2010, pp. 319-321.

doi:10.1038/nbt0410-319

[21] R. Finger, N. El Benni, T. Kaphengst, C. Evans, S. Herbert, B. Bernard Lehmann, S. Morse and N. Stupak, "A Meta Analysis on Farm-Level Costs and Benefits of GM Crops," Sustainability, Vol. 3, No. 5, 2011, pp. 743-762. doi:10.3390/su3050743

[22] V. Beckmann, C. Soregaroli and J. Wesseler, "Coexis- 
tence Rules and Regulations in the European Union," American Journal of Agricultural Economics, Vol. 88, No. 5, 2006, pp. 1193-1199. doi:10.1111/j.1467-8276.2006.00932.x

[23] M. Demont, W. Daems, K. Dillen, E. Mathijs, C. Sausse and E. Tollens, "Regulating Coexistence in Europe: Beware of the Domino-Effect!" Ecological Economics, Vol. 64, No. 4, 2008, pp. 683-689. doi:10.1016/i.ecolecon.2007.10.016

[24] N. Consmüller, V. Beckmann and C. Schleyer, "The Role of Coordination and Cooperation in Early Adoption of GM Crops: The Case of Bt Maize in Brandenburg, Germany," AgBioForum, Vol. 12, No. 1, 2009, pp. 45-59.

[25] B. Tabashnik, A. Gassmann, D. Crowder and Y. Carriére, "Insect Resistance to Bt Crops: Evidence versus Theory," Nature Biotechnology, Vol. 26, 2008, pp. 199-202. doi:10.1038/nbt1382

[26] G. Brookes and P. Barfoot, "Global Impact of Biotech Crops: Income and Production Effects 1996-2007," AgBioForum, Vol. 12, No. 2, 2009, pp. 184-208.

[27] M. Gómez-Barbero, J. Berbel and E. Rodriguez-Cerezo, "Bt Corn in Spain-The Performance of the EU's First GM Crop," Nature Biotechnology, Vol. 26, 2008, pp. 384386. doi:10.1038/nbt0408-384

[28] National Research Council, "Impact of Genetically Engineered Crops on Farm Sustainability in the United States," National Academy of Sciences, Washington DC, 2010.

[29] R. Finger, "Evidence of Slowing Yield Growth-The Example of Swiss Cereal Yields," Food Policy, Vol. 35, No. 2, 2010, pp. 175-182. doi:10.1016/j.foodpol.2009.11.004

[30] G. Brookes, "The Impact of Using GM Insect Resistant Maize in Europe since 1998," International Journal of Biotechnology, Vol. 10, No. 2-3, 2008, pp. 148-166. doi:10.1504/IJBT.2008.018351

[31] C. Schiefer, "Ergebnisse des Anbaus von Bt-Mais in Sachsen," Sächsische Landesanstalt für Landwirtschaft: Freistaat Sachsen, Germany, 2008.

[32] C. Schiefer, R. Schubert, B. Pölitz, A. Kühne, K. Westphal, O. Steinhöfel and A. Schaerff, "Untersuchungen zum Anbau von GVO in Sachsen," Schriftenreihe der Sächsischen Landesanstalt für Landwirtschaft, Sächsische Landesanstalt für Landwirtschaft: Freistaat Sachsen, Germany, 2008.

[33] BVL, "Standortregister, Übersicht Anbau und Freisetzung Gentechnisch Veränderter Organismen nach Bundesländern," Bundesamt für Verbraucherschutz und Lebensmittelsicherheit, Berlin, 2010.

http://apps2.bvl.bund.de/stareg_web/bundeslandStatistic.do

[34] T. Venus, R. Casadamòn, C. Soregaroli and J. Wesseler, "Comparison of Bt and Non-Bt Maize Cultivation Gross Margin: A Case Study of Maize Producers from Italy, Spain and Germany," Final Report, 2011, p. 96. http://utagri.enea.it/sites/default/files/btm_final_report-de f.pdf

[35] M. Gouse, C. E. Pray, J. Kirsten and D. Schimmelpfennig, "A GM Subsistence Crop in Africa: The Case of Bt
White Maize in South Africa," International Journal of Biotechnology, Vol. 7, No. 1-3, 2005, pp. 84-94. doi:10.1504/IJBT.2005.006447

[36] M. Demont and E. Tollens, "First Impact of Biotechnology in the EU: Bt Maize Adoption in Spain," Annals of Applied Biology, Vol. 145, No. 2, 2004, pp. 197-207. doi:10.1111/j.1744-7348.2004.tb00376.x

[37] Troyer, "USDA-National Agricultural Statistics Service Information (NASS)," Crop Science, Vol. 19, No. 2, p. 528.

[38] G. Brookes, “The Farm Level Impact of Using Bt-Maize in Spain," Brookes West, Kent, 2002.

[39] G. M. Dill, C. A. Cajacob and S. R. Padgette, "Glyphosate-Resistant Crops: Adoption, Use and Future Considerations," Pest Management Science, Vol. 64, No. 4, 2008. pp. 326-331.

[40] M. Qaim and D. Zilberman, "Yield Effects of Genetically Modified Crops in Developing Countries," Science, Vol. 299, No. 5608, 2003, pp. 900-902. doi:10.1126/science. 1080609

[41] R. M. Bennett, U. Kambhampati, S. Morse and Y. Ismael, "Farm-Level Economic Performance of Genetically-Modified Cotton in India," Applied Economic Perspectives and Policy, Vol. 28, No. 1, 2006, pp. 59-71. doi:10.1111/j.1467-9353.2006.00273.x

[42] M. Qaim, A. Subramanian and P. Sadashivappa, "Commercialized GM Crops and Yield," Nature Biotechnology, Vol. 27, 2009, pp. 803-804. doi:10.1038/nbt0909-803b

[43] J. Fernandez-Cornejo, A. Mishra, R. Nehring, C. Hendricks, M. Southern and A. Gregory, "Off-Farm Income, Technology Adoption, and Farm Economic Performance/ ERR-36," Economic Research Service/USDA, 2007.

[44] S. Bonny, "Herbicide-Tolerant Transgenic Soybean over 15 Years of Cultivation: Pesticide Use, Weed Resistance, and Some Economic Issues. The Case of the USA," Sustainability, Vol. 3, No. 9, 2011, pp. 1302-1322. doi:10.3390/su3091302

[45] J. Carpenter, "Impacts of GM Crops on Biodiversity," GM Crops \& Food, Vol. 2, No. 1, 2011, pp. 1-17. doi:10.4161/gmcr.2.1.15086

[46] S. E. Naranjo, "Long-Term Assessment of the Effects of Transgenic Bt Cotton on the Abundance of Nontarget Arthropod Natural Enemies," Environmental Entomology, Vol. 34, No. 5, 2005, pp. 1193-1210. doi:10.1603/0046-225X(2005)034[1193:LAOTEO]2.0.C $\underline{\mathrm{O} ; 2}$

[47] J. Romeis, A. M. Shelton and G. G. Kennedy, "Integration of Insect-Resistant Genetically Modified Crops within IPM Programs," Springer, Berlin, 2008. doi:10.1007/978-1-4020-8373-0

[48] Y. Lu, K. Wu, Y. Jiang, Y. Guo and N. Desneux, "Widespread Adoption of Bt Cotton and Insecticide Decrease Promotes Biocontrol Services," Nature, Vol. 487, No. 7407, 2012, pp. 362-365.

http://www.nature.com/nature/journal/vaop/ncurrent/extre f/nature11153-s1.pdf doi:10.1038/nature11153 